\title{
O Binômio - Inflação - Desenvolvimento (II)
}

\section{Chagas Melo}

Os múltiplos aspectos da atual coniuntura econômico-financeira do Brasil são estudados, com bôa técnica, no presente trabalho.

Segundo o autor, foi clecisivo, ao desencadeamento da pressão inflacionária, haver deixado, o govêrno, de selecionar os investimentos e ultrapassado os limites de emissões que poderiam ser considerados benéficos ao desenvolvimento do Pais.

Após analisar a doutrina desenvolvimentista de Keynes e a sua adversa aplicação no Brasil, o autor estuda a receita, representada pela ajuda externa e pelas exportações, insuficiente ao financiamento de nosso desenvolvimento e à cobertura de deficits orçamentários, terminando por recomendar a utgente necessidade de reformulação de financiamento do desenvolvimento economico do Brasil.

FINANCIAMENTO do nosso desenvolvimento econômico através de emissões maciças de papel-moeda não deu os resultados esperados por dois motivos importantes: a) não houve seleção de investimentos; $\mathrm{e} \quad b$ ) se é verdade que um ligeiro sôpro inflacionário pode ser benéfico ao desenvolvimento, o seu exagêro acarreta o desencadeamento de violentas pressões inflacionárias como vem ocorrendo no Brasil.

No planejamento do desenvolvimento econômico dos países subdesenvolvidos o problema do financiamento é básico, seguindo-se uma escala prioritária dos setores que devam merecer maior incremento por parte do Govêrno.

Preliminarmente, não houve um levantamento dos recursos com que poderia contar o Govêrno para custear o seu programa de investimentos: os recursos vinham de várias fontes, como empréstimos externos e internos, recursos provenientes de importação de capital, dotações orçamentárias e quando êsses recursos eram insuficientes como sempre o foram, recorria-se às emissões. 
Depois de criada pela Carta de Punta del Este, em agôsto de 1961, todos os empréstimos externos estão subordinados à "Aliança para o Progresso".

Segundo "Relatório da Comissão Coordenadora da Aliança para o Progresso, órgão da Presidência da República, no periodo de maio de 1961 a outubro de 1962. a ajuda norte-americana somou US\$ 661 m.lhões, dos quais sòmente $61 \%$ ou seja, US\$ 406 milhões foram efetivamente desembolsados, sendo que os restantes US\$ 255 estão paulatinamente sendo liberados.

Nas relações diretas com os Estados apenas o Estado da Guanabara, Pernambuco e alguns Estados do Nordeste foram beneficiados.

O Estado da Guanabara obteve empréstimos para água e esgotos, no valor de US $\$ 35$ milhões e negociações estão sendo levadas a efeito com a Companhia Progresso do Estado para concessão de empréstimos com a finalidade de atender às demandas de capital da pequena e média indústria.

Pernambuco obteve financiamento para integralização de capital da Companhia Pernambucana de Borracha Sintética e para construção de casas populares.

Pelo "Acôrdo do Nordeste", assinado em abril de 1962, pelos Presidentes JoÃo Goulart e JoHN KenNEdy, foram reservados à S.U.D.E.N.E. para emprêgo no Nordeste, US\$ 131 milhõos. Posteriormente, novos acôrdos foram assinados num total de US\$ 17 milhões para abastecimento de água em cidades e capitais da referida região.

O Estado de Minas Gerais já deve ter recebido o auxílio de US\$ 6 milhões para execução do programa de colonização que está sendo executado pelo ilustre Governador Magalhães Pinto.

Os empréstimos internos são cobrados como adicionais ao impôsto de renda e recolhidos e aplicados pelo Banco Nacional do Desenvolvimento Econômico.

Desde sua criacão de 1952, o Banco aplicou a soma de $\mathrm{Cr} \$ 59.532 .225 .000 .00$, distribuidos segurdo o Relatório de suas atividades para 1960, da seguinte forma: a) 10 bilhões para transporte; b) 16 bilhões para energia elétrica; c) 24 bilhões para indústrias básicas; e $d$ ) 10 bilhões para metalurgia, e outros ramos sem grande expressão estatística.

Os recursos do Banco de Desenvolvimento Econômico foram aplicados, $85 \%$ na Região Centro-leste, restando apenas 15\% para as demais regiôes do País. Tais recursos foram empregados na produção de aquipamentos ou de criação de condições básicas para o desenvolvimento econômico, como energia elétrica e transporte. 
No setor agricola a ação do Banco foi quase nula, à exceção de pequenos financiamentos para construção de armazens e silos, e uma ou duas fábricas de fertilizantes.

Se levarmos em conta que em 4 anos, de 1947 a 1960, foram gastos em Brasilia, 150 bithões de cruzeiros, verificamos que os investimentos a que acima aludimos foram insignificantes em face de nossas necessidades.

Do setor externo, como vimos, os empréstimos foram insuficientes para atender às nossas necessidades de demanda de capital. No que respeita às importações financiadas pelas exportações a situação tornou-se mais dramática, pois, estas se mantiveram em têrmos monetários, sem variaçôes, como se vê do quadro abaixo:

$\begin{array}{lcc}\text { Ano } & \text { Exporta̧̧̋́es } & \text { US\$ mithões } \\ 1958 & - & 1.243 .0 \\ 1959 & - & 1.282 .0 \\ 1960 & - & 1.268 .8 \\ 1961 & - & 1.403,0 \\ 1962 & - & 1.214,2\end{array}$

A exceção do ano de 1961 que recebeu um impulso decorrente da Instrução 204 da S.U.M.O.C., nos demais anos as exportações permaneceram as mesmas, quando as necessidades de importação aumentaram e foram refreadas pela falta de divisas, prejudicando o nosso desenvolvimento econômico.

Assim, o setor do comércio exterior não contribuiu, como era de esperar, para o financiamento do nosso desenvolvimento.

O setor do comércio exterior precisa ser reformulado em dois pontos principais: a) intensificação da exportação de produtos manufaturados, pois os produtos primários vêm sofrendo uma deterioração de preço no mercado internacional tendo como um dos motivos principais a superprodução; e $b$ ) ampliação da área geográfica de comércio.

Como uma dos fatôres de incremento das exportaçóes, além do aspecto cambial por uma melhor remuneração, ressaltamos o problema fiscal, ou seja isenção de impostos para produtos ex-
portados.

Em 1962, na última reforma do impôsto de consumo, ficar ram isentas do impôsto as mercadorias exportadas, bem como as matérias-primas importadas através do instituto conhecido como "draw-back", que consiste na devolução do impôsto pago quando as referidas matérias-primas forem empregadas em produtos in-
dustriais exportados. 
As isenções dos impostos acima mencionados não têm favorecido como estimulos fiscais às exportações, não sòmente pela dificuldade no recebimento e na devolução dos impostos pagos, como pelo fato dos maiores gravames fiscais advirem do sistema de cobrança do impôsto de vendas e consignações conhecido como "cascade systeme" onde as mercadorias são taxadas duas ou três vêzes até serem exportadas, além do pagamento do antieconômico impôsto de exportação que deveria, através de uma emenda constitucional, passar ao âmbito federal.

A receita federal tem sido insuficiente para cobrir os "deficits" orçamentários oriundos de subvenções às emprêsas governamentais tradicionalmente deficitárias e das despesas de custeio inclusive as de pessoal civil e militar. As despesas de investimentos somam apenas a pouco mais de $30 \%$ do total do orçamento do govêrno federal, o que vêm confirmar que os investimentos governamentais têm sido feitos à custa de emissões de papel-moeda, com reflexos no padrão de vida do povo brasileiro que sofre os efeitos da alta de preços.

Assim, financiar o nosso desenvolvimento econômico através de processos inflacionários, é sumamente perigoso em face dos resultados obtidos no Brasil.

Esse êrro, aliás, vem de longa data, agravado em determinados períodos governamentais, alegando os seus defensores que foi LoRD KEYNES em duas obras de grande importância, uma de 1930, Theory of Money, outra de 1936. General Theory of Employment, Interest and Money, quem sustentou a compatibilidade do desequilibrio monetário com a melhoria do padrão de vida da coletividade.

A "Revista Técnica e Financeira da Indústria e Comércio", de novembro dezembro de 1961 , em editorial, comentando a teoria de KEYNES sôbre o financiamento do desenvolvimento econômico, disse o seguinte:

"Esta é, pois, a teoria de KEYNes que é, afinal de contas, a teoria inflacionista posta em prática no Brasil e ardentemente defendida pelos círculos econômicos governamentais que, no periodo de 1955-1960 lançou o que se convencionou chamar desenvolvimentismo".

"Entretanto, continua a Revista, há que fazer dois reparos, o primeiro à aplicação, no Brasil, da politica keynesiana nas atuais circunstâncias de nossa economia e o segundo, à própria essência da teoria de KEYNES.

“O primeiro é que a política keynesiana foi posta em prática com grande sucesso para combater justamente o fenômeno opôsto do que entre nós ocorre, ou seja a depressão. Foi adotada se- 
melhante politica para atingir o que se considera a normalidade econômica ideal ou seja o pleno emprêgo dos fatôres de produção. Depois que os Estados Unidos recuperaram-se da depressão, procuraram sempre manter o equilibrio econômico da nação evitando cair na inflação. No Brasil, a política desenvolvimentista vem aplicar as teses de Keynes num pais em que, na prática, ela sempre foi praticada. Como resultado teremos a aceleração cada vez maior da inflação. Cabe a nós decidir: isto será um bem?

O segundo reparo, como já díssemos, é feito à própria teoria keynesiana: é que a redistribuição da renda nacional, por KYNES preconizada, não ocorre, a não ser que se parta de uma posição de equilibrio. E' preciso haver o fator surprêsa a fim de que os elementos que vivem de rendas contratuais não saibam de antemão que se pretende provocar aquela redistribuição. Se já existe essa expectativa é evidente que a tendência do individuo que vive de renda contratual é assumir uma posição de precaução, levando-o a incluir em seus contratos a expectativa de uma futura depreciação da moeda. O que ocorre é que inicia-se complexa luta social pelos privilégios da renda inflacionada. Surge a tão conhecida espiral "custos-prêços", o que nos leva a comprender por que em 1954 duplicou-se o salário-minimo e nos recentes dissidios coletivos os aumentos sempre superaram a elevação dos preços. A expectativa de que os preços serão ainda mais altos no futuro, leva os assalariados a incluirem em seus contratos presentes a certeza da inflação futura. O melhor exemplo do que seja a luta em redor da espiral "custos-preços" é o chamado salário-móvel. O Chile, que mantinha um rítmo de aumento de preços de $25 \%$ a $30 \%$ ao ano (o mais elevado da América Latina), adotou o salário-móvel. O resultado foi que o nivel dos preços atingiu um aumento de $80 \%$ ao ano, forçando o abandôno
ła escala móvel.

Antes de terminar, diz a Revista, queremos lembrar que a mais aceita tese moderna é a dos chamados ciclos inflacionários, à qual se filia o economista brasileiro RoBerto CAMPos. Considera esta tese que o ideal para a economia de um país é ter periodos de pequena inflação seguidos por periodos de estabilidade. Consegue-se, assim, o elemento surprêsa, implicito na tese de Keynes. Se, durante algum tempo, a estabilidade dos preços puder resultar em pessimismo para os homens de negócios e não os estimular a fazer novas inversões, então deve haver, na economia do pais, um pequeno desequilibrio monetário, para a aceleração dos negócios voltando-se em seguida ao periodo de estabi-
lidade".

Já está suficientemente provado que o desenvolvimento eco. nômico bräsileiro não pode ser financiado através de processos 
inflacionários e sòmente pode se admitir um ligeiro sôpro de inŁlação.

O problema do financiamento de nosso plano de investimentos deve assentar-se em um esquema misto de empréstimos externos, atração de capitais privados, poupanças internas através de uma reforma tributária e, para investimentos de produtividade imediata, emissões de papel-moeda.

Em recente estudo, o ilustre homem público Deputado ALDE Sampaio, no artigo $A$ Inflação e o Desenvolvimento Econômico diz o seguinte:

"Quando se trata de deficiência de poupança, ainda que por motivo da redução do crédito, a emissão só constitui fator interno de desenvolvimento econômico, se o dinheiro emitido é colocado em investimento produtivo; e, nas mesmas condições, poderá vir a sê-lo,, quando se trate de conjuntura onde haja excesso de entesouramento ou poupança paralizada.

Contudo, continua o Deputado Alde Sampaio, pelas circunstâncias que acarreta, pelo dano que possa trazer quer ao bem-estar da população, quer à prosperidade dos empreendimentos em curso e pelos problemas legais que cria, a emissão inflacionária só se justifica quando não seja possivel aumentar o desenvolvimento econômico por outros meios mais aconselháveis". (Deputado Alde Sampaio, artigo citado).

"Do ponto-de-vista social, a inflação, pràticamente, já esgotou suas possibilidades de financiar o desenvolvimento econômico brasileiro. E' principalmente por êsse motivo que, na impossibilidade de contê-la a curto prazo por intermédio de uma politica de estabilização ortodoxa que ponha em risco o nosso desenvolvimento, novos esquemas de politica econômica de natureza qualitativa começam a ser delineados, e já estão penetrando na arena politica. Tais esquemas, que são as chamadas reformas de base, visam, a longo prazo, a aumentar o ritmo da mudança estrutural e a diminuir as pressões inflacionárias", foi o que escreveu o Prof. Jamil Munhoz Bailão em artigo "Conjuntura EconômicoFinanceira do Brasil" (Revista do Conselho Nacional de Economia- março-agôsto de 1963.

Por todos êsses motivos, é que devemos reformular o financiamento do nosso desenvolvimento econômico em outras bases, sem utilizar emissões com base de um programa de investimentos. 